\title{
Field-Identification IAT predicts students' academic persistence over and above Theory of Planned Behavior constructs
}

\author{
Nathalie Roland $^{\mathrm{a}}$, Adrien Mierop ${ }^{\mathrm{a}}$, Mariane Frenay ${ }^{\mathrm{a}}$, Olivier Corneille ${ }^{\mathrm{a}}$ \\ âniversité catholique de Louvain, Belgium
}

Article received 8 September 2017 / Article revised 3 November / Accepted 20 March / Available online April 302018

\begin{abstract}
Ajzen and Dasgupta (2015) recently invited complementing Theory of Planned Behavior (TPB) measures with measures borrowed from implicit cognition research. In this study, we examined for the first time such combination, and we did so to predict academic persistence. Specifically, 169 first-year college students answered a TPB questionnaire and completed a field-identification Implicit Association Test (IAT). The IAT measure largely predicted academic persistence 6 months later over and above $T P B$ constructs, including behavioral intention. We discuss interpretations of this finding and its relevance to educational research.
\end{abstract}

Keywords: Theory of planned behavior; Implicit association test; Academic persistence; College students; Field-identification 


\section{Introduction}

Dropout in first year at university affects about $25 \%$ of students, and comes with major social, organizational and economic costs (Finnie \& Qiu, 2008; National Center for Education Statistics, 2016; Organization for Economic Cooperation and Development, 2013; Schmitz \& Frenay, 2013). Over the last 30 years, education research has significantly advanced our understanding of the drivers of students' persistence and drop out. Historically, researchers have focused on the socio-demographic characteristics of students (e.g., ethnicity, parent income, parent's third-level education, sex, educational background) to understand academic persistence (Otero, Rivas, \& Rivera, 2007; Pascarella \& Terenzini, 2005; Ratelle, Larose, Guay, \& Senécal, 2005; Vermandele, Dupriez, Maroy, \& Van Campenhoudt, 2012). In parallel, researchers started exploring the role of motivational variables (e.g., expectancy-value, intention, self-efficacy, control) and educational variables (e.g., institutional experiences, academic and social integration, social pressure) (Braxton, Hirschy, \& McClendon, 2004; Cabrera, Castaneda, Nora, \& Hengstler, 1992; Eccles \& Wigfield, 2002; Nora, Cabrera, Hagdorn, \& Pascallera, 1996; Pritchard \& Wilson, 2003; Schmitz, Frenay, Neuville, Boudrenghien, Wertz, Noël, \& Eccles, 2010; Tinto, 2006). In this context, the Theory of Planned Behavior (or TPB; Fishbein \& Ajzen, 2010) was recently considered, with the aim of covering under a single theoretical umbrella the most widely studied determinants of academic persistence (Davis, Ajzen, Saunders, \& Williams, 2002; Houme, 2010; Roland, Frenay, \& Boudrenghien, 2016a).

In TPB research, people's behavior is thought be best predicted by their intention to perform this behavior. In turn, people's intentions are determined by their attitudes, perceived norms and perceived control. Those are all ultimately based on their beliefs that the behavior is likely to be under their control and to serve their best interests. This rational behavioral model relies on direct (i.e., self-reported) measures of TPB constructs, such as self-reported intentions (Fishbein \& Ajzen, 2010). The TPB provided a very integrative understanding of academic persistence (Davis et al., 2002; Houme, 2010; Roland et al., 2016a). Recently, however, prominent TPB and implicit cognition researchers have called for studies that include both direct and indirect measures for predicting behavior. For instance, Ajzen and Dasgupta (2015) noted:

"Complementing the reasoned action approach, a great deal of research in recent years has focused on implicit cognitions and their effects on behavior. The general theorizing behind this line of work is the proposition that dormant beliefs, attitudes, intentions, and other constructs of this kind can be activated while still remaining below conscious awareness, and that these implicit reactions can have observable effects on judgments and actions" (Ajzen \& Dasgupta, 2015, p. 136)

In the present study, we examined how the latter combination between explicit and implicit cognition measures may help to better predict academic persistence. We did so by collecting both TPB constructs measures and a field-identification Implicit Association Test (IAT) measure. The IAT has been extensively used in implicit cognition research (Hofmann, Gschwendner, Nosek, \& Schmitt, 2005; Rothermund \& Wentura, 2004). It makes it possible to assess spontaneous associations between one's self-concept and semantic attributes (Greenwald et al., 2002). The use of an IAT has been shown to improve the prediction of behaviors in many areas (e.g., mental and physical health, employment, job performance, stereotypes), but to our knowledge it has never been used in the context of academic persistence. And, perhaps even more important, to our knowledge, the IAT and the TPB have never been jointly considered in predicting behaviors. Hence, the innovation of the current research is twofold: examining how an IAT measure contributes to predicting academic persistence, and examining the degree to which it may do so over and above more analytical (and self-reported) TPB measures. In doing so, this research also contributes to strengthening ties between two areas of psychology that are rarely related to each other, namely educational psychology and social psychology (both in its explicit and implicit cognition dimensions).

At first sight, everything opposes the TPB and the IAT approaches, since the first involves detailed and deliberate measures that address explicit cognition processes whereas the second involves holistic and spontaneous measures thought to tackle implicit cognition processes. The use of both direct and indirect measures can, however, help better predict a variety of behaviors, such as intergroup behavior (e.g., 
Greenwald, Mcghee, \& Schwartz, 1998; Ottaway, Hayden, \& Oakes, 2001), job performance (e.g., Srivastava \& Banaji, 2011), and alcohol and drug use (e.g., Chassin, Presson, Sherman, Seo, \& Macy, 2008; Wiers, Van Woerden, Smulders, \& de Jong, 2002). Furthermore, social behaviors characterized by relatively high levels of involvement, such as political voting (e.g., Arcuri, Catselli, Galdi, Zogmaister, \& Amadori, 2008), participation in rallies (e.g., Zerhouni, Rougier, \& Muller, 2016), or even suicidal behavior (e.g., Nock et al., 2010) are often best predicted when using both direct and indirect measures.

We reasoned that the predictive contribution of indirect measures could also be observed in the case of academic persistence. This is consistent with evidence suggesting that for some students vocational decisions are based on a deliberate decision-making style, while for other students the decision is more intuitive (Arroba, 1977; Gati, Landman, Davidovitch, Asulin-Peretz, \& Gadassi, 2010). In fact, Gati and colleagues (2010) proposed that, for the same person, the vocational decision might be based on different decision-making styles. On the basis of these elements, it seemed important to examine the role played by more spontaneous and intuitive process in academic persistence. A field-identification IAT seems particularly suited in this regard.

\section{Method}

\subsection{Participants}

169 first-year Belgian college students in psychology agreed to participate in our research and were assured of the confidentiality of their responses. $86.4 \%$ of the participants were female and $13.6 \%$ were male. This ratio is representative of students in psychology at the hosting university. The mean age of the participants was 19.72 years $(S D=1.02)$. All participants were French speakers. Among these participants, $34.3 \%$ dropped out whereas $66.7 \%$ persisted in psychology studies. Note that no observation was excluded from our sample. This sample size provided adequate statistical power $(1-\beta=.8)$ with a type I error of .05 to detect an effect size as small as Cohen's $\mathrm{f}^{2}=.046$ (which consists of a small-to-medium effect size that is suited for multiple regressions design according to Cohen (1988)).

\subsection{Procedure}

In April 2016, students enrolled in first year psychology -since September 2015- were asked to complete an IAT and a TPB questionnaire. Completion of both the IAT and the TPB questionnaire was confidential and participants collaborated on a voluntary basis. The study was carried out in accordance with the ethical standards of our institution. Those who agreed to participate in this research took the IAT in a computer room and completed a TPB questionnaire directly afterwards. The total duration of task completion was 15 minutes on average. In September 2016, with permission from both the academic authorities and the participants, we obtained information about participants' registration for the next year in their academic program (i.e., persistence measure).

\subsection{Measurement}

Implicit Association Test. The IAT (Greenwald et al., 1998) is a computer test based on participants' response times in classifying stimuli. It measures spontaneous associations between concepts, in this case selfconcept and psychology. More specifically, the IAT consisted of 7 consecutive blocks in which participants had to quickly categorize words appearing on the screen along two dimensions by using two keys ("e" and “i”). The words used to represent the self-concept came from the literature (i.e., Nock et al., 2010; Nosek, Banaji, \& Greenwald, 2002) and the words used to represent psychology were selected on the basis of a pilot study (see Table 1) (Bellezza, Greenwald, \& Banaji, 1986). The pilot study was conducted on a separate sample 
of 159 participants who responded to a solicitation on a popular social network. Respondents came from different backgrounds ( $15 \%$ were professionals in various fields of psychology). The pilot study allowed selecting seven words highly associated with psychology $(M=35.63, S D=11.76)$ and seven words highly associated with other professional and curricula domains $(M=-38.46, S D=12.75)(F(1,15)=2762.6, p<$ $\left..001, \eta^{2}=.95\right)$.

Table 1

Words used in the Implicit Association Test in French (English)

\begin{tabular}{llll}
\hline Self-related & Non-self-related & Psychology-related & Non-psychology-related \\
\hline Mon (Mine) & Leur (Their) & Burnout (Burnout) & Archéologie (Archeology) \\
Je (I) & Il (He) & Dépression (Depression) & Comptabilité (Accounting) \\
Mes (Mines) & Ses (His) & Phobie (Phobia) & Sol (Ground) \\
Ma (Mine) & Sa (Her) & Névrose (Nevrosis) & Eprouvette (Test tube) \\
Mienne (Mine) & Eux (Them) & Emotion (Emotion) & Pesticide (Pesticide) \\
& & Freud (Freud) & Bâtiment (Building) \\
& & Thérapeute (Therapist) & Agricole (Agricultural) \\
\hline
\end{tabular}

In the first block, students had to categorize five words related to the self (e.g., "Me", "Mine") and five words related to others (e.g., "He", "His") by using the "e" key of the keyboard if it was self-related, and by using the " $i$ " key if it was related to others. Participants were instructed to be as quick as possible while trying to make as few mistakes as possible. Each word was presented twice, resulting in 20 trials. In the second block, students had to categorize seven words related to psychology (e.g., "Emotion", "Therapist") with the "e" key and seven words related to other disciplines (e.g., "Accounting", "Archeology") with the "i" key in 20 trials (each word was presented at least once). In the third block and fourth blocks, both self- and psychologyrelated words were to be responded to with the "e" key and the non-self and non-psychology related words with the "i" key. These third and fourth "congruent" blocks consisted in 20 and in 40 trials, respectively. In a fifth block, students were asked to reverse the key mapping for the words related to psychology (by using the "i" key) or not psychology (by using the "e" key) in 20 trials. In the sixth and seventh "incongruent blocks", students had to categorize words using the "e" key both for self-related and non-psychology related words and the "I" key" for the no-self related and the psychology-related words, respectively for 20 and 40 trials. Students were randomly assigned to a condition in which congruent blocks preceded the incongruent blocks or viceversa (reversing blocks 2, 3 and 4 with blocks 5, 6 and 7). As a result, depending on the experimental block, students had to use the same key or not to categorize the words as related to the self and to psychology. The rationale is that if they associate themselves strongly with psychology, categorizing self-related words along with psychology-related words should be facilitated. Likewise, categorizing self-related words with nonpsychology-related words using the same key should interfere (Greenwald et al., 1998 ; Hofmann et al., 2005).

The relative strength between "self" and "psychology" was computed for each participant by calculating a D score $[-2 ;+2]$ (Nosek, Bar-Anan, Sriram, Axt, \& Greenwald, 2014). According to Nosek and colleagues (2014), response times exceeding $10.000 \mathrm{~ms}$ and/or students with more than $10 \%$ of their response time below $300 \mathrm{~ms}$ had to be excluded from the sample. Indeed, Nosek and colleagues (2014) found that including very fast responses $(<300 \mathrm{~ms})$ or on the contrary slow responses $(>10.000 \mathrm{~ms})$ disrupted 
psychometric properties enough to warrant excluding them. Based on these rules, none of the participants of this study had to be excluded from the sample. To calculate the $D$ score, the average response time of the congruent blocks was subtracted from the average response time of the incongruent blocks and this score was then divided by the standard deviation of response times per participant. The $D$ score thus represents the level of spontaneous identification of the self with psychology, a positive $D$ score meaning a stronger association between "self" and "psychology" and a negative D score meaning a stronger association between "self" and "not psychology".

Persistence. To measure persistence, we used the student's registration in the same field of studies in the next academic year (Nora et al., 1996; Robbins et al., 2004). Students who continued in the same field after their first academic year were coded " 1 "; students who did not continue in the same field were coded " 0 ".

To measure the constructs of the theory of planned behavior, we used scales adapted from Fishbein and Ajzen (2010). Most items on the self-report questionnaire were rated on 5-point Likert-type scales (generally with $1=$ strongly disagree and $5=$ strongly agree). The exceptions are presented below. Factorial analyses were performed and revealed one factor by scale, except for perceived behavioral control where three factors were found.

Intention. Students' intention to persist was assessed using three items $(\alpha=.88)$ ("I intend to stay registered in psychology studies next year").

Attitude. The evaluation of attitude was obtained by means of a set of evaluative semantic differential scales. The statement "Staying enrolled in psychology studies next year will be..." was rated on five bipolar adjective scales (pleasant-unpleasant; positive-negative; useful-useless; good-bad; important-not important) taken from Osgood, Suci and Tannenbaum (1957) $(\alpha=.89)$.

Injunctive norms. Four items were used to measure injunctive norms $(\alpha=.71)$. One item was "My relatives believe that I should not stay enrolled in psychology studies next year".

Descriptive norms ${ }^{l}$. Six items were used to assess descriptive norms concerning their father and mother $(\alpha=.77)$. One item was "During her studies, my mother remained enrolled in the studies she had initiated".

Perceived behavioral control. Ten items were created for assessing perceived behavioral control, following the recommendations of Fishbein and Ajzen (2010). Factorial analysis revealed three factors. The first factor was composed of four self-efficacy items $(\alpha=.85)$ ("I am sure that I will be able to stay enrolled in my psychology studies next year"). The second factor consisted of three items about the control a person has over the decision to drop out $(\alpha=.86)$ ("I will decide to enroll in new studies next year"). Finally, the third factor was about control a person has over the decision to persist and was made up of two items ( $\mathrm{r}=.75$ ) ("I'll decide to stay enrolled in psychology next year").

\section{Results}

\subsection{Preliminary analyses}

Correlational analyses and summary statistics of each study's variables were performed (Table 2). The scores corresponding to Skewness and Kurtosis were found to be within the normal values (Hae-Young, 2013). Correlational analyses showed outcomes consistent with relationships postulated in the TPB (for more details on TPB applied to academic persistence, see Houme, 2010; Roland et al., 2016a).

It is interesting to note that the IAT was significantly correlated with persistence, and with persistence only. Performance on the IAT was compared, using a $t$ test for independent samples, between students who

\footnotetext{
${ }^{1}$ This scale, although part of the TPB, was not taken into account in all the analysis since only students with at least one graduate parent could answer this question. This therefore excluded many of the participants.
} 
persisted and students who gave up. Results revealed that students who persisted initially had a stronger implicit association between self and psychology $(M=.82, S D=.37)$ than those who eventually decided to drop out six months later $(M=.47, S D=.40)(t(167)=5.76 ; p<.001)$.

Table 2

Correlations between the TPB constructs and the IAT

\begin{tabular}{|c|c|c|c|c|c|c|c|c|c|c|c|c|c|}
\hline & $\mathrm{M}$ & SD & Skew. & Kurt. & 1. & 2. & 3. & 4. & 5 . & 6. & 7. & 8. & 9. \\
\hline 1. Persistence & .65 & .48 & -.67 & -1.57 & 1 & $.41^{* *}$ & $.19^{*}$ & .07 & $.19 * *$ & .01 & $.20 * *$ & .02 & .11 \\
\hline 2. IAT & .70 & .42 & -.32 & 1.41 & & 1 & -.02 & -.03 & -.05 & -.01 & .01 & -.13 & -.08 \\
\hline 3. Intention & 4.68 & .71 & -2.52 & 3.4 & & & 1 & $.63 * *$ & $.36^{* *}$ & -.12 & $.50 * *$ & $.17 *$ & -.09 \\
\hline 4. Attitude & 4.56 & .49 & -1.22 & 1.01 & & & & 1 & $.37 * *$ & -.08 & $.43 * *$ & $.18 *$ & -.07 \\
\hline $\begin{array}{l}\text { 5.Injunctive } \\
\text { norms }\end{array}$ & 4.24 & .68 & -.91 & .23 & & & & & 1 & -.02 & $.33 * *$ & .13 & -.04 \\
\hline $\begin{array}{l}\text { 6.Descriptive } \\
\text { norms }\end{array}$ & 4.04 & 1.25 & -.61 & -.51 & & & & & & 1 & .52 & .32 & .05 \\
\hline $\begin{array}{l}\text { 7.Self-efficacy } \\
\text { beliefs }\end{array}$ & 4.28 & .65 & -.79 & -.17 & & & & & & & 1 & $.20 * *$ & .11 \\
\hline $\begin{array}{l}\text { 8.Control on } \\
\text { persistence }\end{array}$ & 4.85 & .43 & -2.48 & 4.01 & & & & & & & & 1 & .08 \\
\hline $\begin{array}{l}\text { 9. Control on } \\
\text { dropout }\end{array}$ & 3.21 & 1.49 & -.30 & -1.35 & & & & & & & & & 1 \\
\hline
\end{tabular}

$* *=p<.01 ; *=p<.05$

\subsection{Main analyses}

Of critical interest to the present research is whether the field-identification IAT would predict persistence over and above TPB measures. To this end, we ran a logistic regression analysis that regressed persistence on TPB and IAT measures (see Table 3). Logistic regression is the appropriate regression analysis to conduct when the dependent variable is dichotomous. This analysis showed that self-reported intention and the IAT measure predicted persistence in this joint model $^{2}$. Of importance, intention was less predictive of persistence than the IAT measure: the odds of persisting were much higher when the IAT score was high ( $\exp$ $b=18.25)$ than when intention was high $(\exp b=2.28)$.

\footnotetext{
${ }^{2}$ That other constructs of TPB do not predict persistence in this model is not surprising since they are supposed to impact persistence through intention. Preliminary analyses showed that when intention is not introduced into the regression, self-efficacy predicts persistence, which is consistent with research (Barry \& Finney, 2009; Vuong, Brown-Welry, \& Tracs, 2010; Wright, Jenkins-Guarnieri, \& Merdock, 2012). Table 1 also shows simple correlations between those constructs, intentions and persistence, which are fully consistent with TPB.
} 
Table 3

Logistic regression analysis predicting academic persistence

\begin{tabular}{lll}
\hline & $\boldsymbol{B}(\boldsymbol{S E})$ & $\exp \boldsymbol{b}$ \\
\hline Constant & $-5.18(2.74)$ & .01 \\
Attitude & $-.88(.52)$ & .42 \\
Injunctive norms & $.56(.31)$ & 1.74 \\
Self-efficacy beliefs & $.48(.35)$ & 1.62 \\
Control on persistence & $.05(.48)$ & 1.05 \\
Control on dropout & $-.15(.14)$ & .86 \\
Intention & $.83(.38)$ & $2.28^{*}$ \\
IAT & $2.90(.59)$ & $18.25^{* * *}$ \\
\hline$R^{2}($ Cox \& Snell $)=.26 ; R^{2}($ Nagelkerke $)=.36 ;$ Model $\chi^{2}(\mathrm{df})=51.07(7) * * *$ & \\
$* p<.05 ; * * * p<.001$ & &
\end{tabular}

\section{Discussion}

The general goal of this research was to follow a recent invitation to examine the joint contribution of TPB and implicit cognition measures for predicting social behaviors (Ajzen \& Dasgupta, 2015). We did so by combining a TPB measure and a field-identification IAT measure to predict academic persistence. In doing so, we combined for the first time TPB and IAT measures to predict a behavior. As an additional asset, we also introduced for the first time a measure borrowed from implicit cognition in academic persistence research, the latter of which has extensively relied on self-reported measures, so far (e.g., Cabrera et al., 1992; Eccles \& Wigfield, 2002; Pascarella \& Terenzini, 2005; Roland et al., 2016a; Schmitz et al., 2010; Tinto, 2006). The measure that best illustrates this deliberate approach is students' intention to persist (Braxton, Bray, \& Berger, 2000; DaDeppo, 2009; Schmitz \& Frenay, 2013). In contrast, the use of more indirect measures has never been examined in research on academic persistence, although it was examined in research on vocational choice (Arroba, 1977; Gati et al., 2010).

We found that the field-identification IAT measure (i) strongly predicts persistence (i) strongly predicts it over and above comprehensive TPB measures, and (iii) predicts, by a large margin, persistence more strongly than TPB measures do, when collected six months ahead of students' actual persistence decisions.

These findings may be interpreted in different ways. One interpretation is that unconscious determinants of people's behavior operate independently of people's conscious beliefs and deliberate intentions. At first sight, this interpretation is consistent with our finding that the IAT measure was uncorrelated with TPB measures and that the association between the IAT measure and persistence was not mediated by intentions (as IAT and intentions were not associated with each other). We do not subscribe to this latter interpretation. As a matter of fact, recent research shows that constructs measured by the IAT can be formed through fully deliberate learning processes (e.g. Gast \& De Houwer, 2012; Kurdi \& Banaji, 2017; Van Dessel, De Houwer, Gast, \& Smith, 2015) and that people are able to consciously introspect their IAT score (Hahn, Judd, Hirsch, \& Blair, 2014). More generally, that indirect measures reflect the operation of either independent 
learning pathways or behavioral expression pathways has been questioned lately (for a recent discussion, see Corneille \& Stahl, 2018)

Instead, the current findings may suggest that students' intentions are less stable than their identification to the field. As time goes by, students may experience situations that lead them to revise their beliefs and so update their attitudes, perceived norms, sense of control, and ultimately their intention to persist. This is in line with research showing that temporal distance weakens the intention-to-behavior association (McEachan, Conner, Taylor, \& Lawton, 2011; Sheeran, Orbell, \& Trafimow, 1999). This second interpretation suggests that the predictive advantage of the IAT resides in the higher stability of the construct it tackled (i.e., identification to the field). For instance, in the first months of their studies, many students are disappointed that they have to attend very general courses (e.g., physiology and statistics) instead of more specialized psychology courses (Neuville, Frenay, \& Bourgeois, 2007; Roland, Frenay, \& Boudrenghien, 2016b). Those students may thus revise their intention to persist in a program that does not fulfill their expectations, while still feeling attracted to psychology in general (Roland et al., 2016b). Field-identification may be less sensitive to the latter disappointment and motivate students to persist in their studies. If this interpretation is correct, one may speculate that for students more advanced in their curriculum, the predictive gap between intention and IAT measures decreases (as the courses become more specialized from year to year). One may also predict that, within the first year, the IAT-intention predictive gap decreases over the year, and also that the IAT measure is more stable than the intention measure. Finally, one may predict this IAT-intention predictive gap to be smaller in academic fields where students' expectations about curricula are possibly more realistic (e.g., mathematics, engineering). The hypothesis that the IAT measure was more stable than the direct measure of intention should, however, be confirmed in a longitudinal study.

In any case, when it comes to the question of which measure may be favored for diagnostic purposes, the current analysis clearly supports the field-identification IAT, at least for the student population considered here, one that suffers from massive dropout rates in the first year (Romainville \& Michaut, 2012). This conclusion is in line with research showing that the link between intention and persistence is highly variable and typically weak (Bers \& Smith, 1991; Cabrera et al., 1992; Pascarella, Duby, \& Iverson, 1983; Sandler, 2000). Note that an interesting question for future research is whether a deliberate field-identification measure may not serve the same purpose, for instance using a self-reported pictorial self-categorization measure (Schubert \& Otten, 2002). Answering this question would be of paramount interest for both implicit cognition theorization and academic guidance. One possibility is that IAT and deliberate identification measures complement each other. Alternatively, a field-identification IAT may outperform, as this measure is likely to be less contaminated by social demands and introspective effects.

Finally, another interesting finding of the current research is that a precise and deliberate behavior can be better predicted by an IAT measure than by several TPB questions. Two comments have to be made here. First, this finding may seem inconsistent with the compatibility principle inherent in the TPB, which states that a specific behavior is best predicted by a diversity of precise questions (at least when they are separated by a significant time delay). Again, however, it should be noted that TPB measures were probably collected here too early to secure their maximum predictive value. Second, the fact that the IAT measure predicted a behavior as deliberate as persisting in an academic curriculum may seem problematic for research suggesting doubledissociations in measure and behavior types such that deliberate and conscious behaviors would be best predicted by self-reports whereas more automatic behaviors would be best predicted by indirect associative measures as the IAT (e.g., Friese, Hofmann, \& Schmitt, 2009; Hofmann et al., 2005). However, numerous studies, along with the present one, have reported findings inconsistent with the dissociative view. For instance, IAT measures have been shown to successfully predict behaviors as deliberate as political votes (Arcuri et al., 2008) or suicide attempts (Nock et al., 2010).

The present results should be interpreted in the light of several limitations, which call for future research. First, this study was conducted only with psychology students. As discussed above, it is important to replicate this study with students from other faculties, and also from other universities. To achieve this, it would be necessary to conduct pilot studies to identify stimuli relevant to each field of study (Greenwald et al., 1998; Nosek, Banaji, \& Greenwald, 2010). Second, the stimuli used in the IAT tested here focused mostly 
on clinical psychology. These stimuli stem from the pilot study we carried out and may therefore be considered as valid. Although the resulting IAT predicted overall academic persistence in psychology, it is possible that some students, who were attracted to other fields of psychology (e.g., work psychology), felt less identified with these stimuli and that for these students the IAT was less predictive of their specific future persistence.

Despite its limitations, however, this study provides a first test of the role of implicit cognition measures in predicting academic persistence, and more generally in complementing TPB measures. Neither of these objectives was empirically addressed so far. Indeed, direct measures are by very far the dominant norm in educational research. This more generally points to the interest of bringing different fields of research together; in the present case, educational and social psychology.

\section{Keypoints}

- Academic persistence is predicted by both direct and indirect measures.

- A field-identification Implicit Association Test strongly predicts students' academic persistence six months ahead of decision, over and above Theory of Planned Behavior measures.

- The interpretations of this finding and its relevance to educational research are discussed.

\section{References}

Ajzen, I., \& Dasgupta, N. (2015). Explicit and implicit beliefs, attitudes, and intentions: The role of conscious and unconscious processes in human behavior. In P. Haggard, \& B. Eitam (Eds.), The sense of agency (pp. 115-144). New York: Oxford University Press.

Arcuri, L., Castelli, L., Galdi, S., Zogmaister, C., \& Amadori, A. (2008). Predicting the vote: Implicit attitudes as predictors of the future behavior of decided and undecided voters. Political Psychology, 29(3), 369-387. doi: 10.1111/j.1467-9221.2008.00635.x

Arroba, T. (1977). Styles of decision making and their use: An empirical study. British Journal of Guidance and Counselling, 5, 149-158. doi: 10.1080/03069887708258110

Barry, C. L., \& Finney, S. J. (2009). Can we feel confident in how we measure college confidence? A psychometric investigation of the college self-efficacy inventory. Measurement and Evaluation in Counseling and Development, 43(3), 197-222. doi: 10.1177/0748175609344095

Bellezza, F. S., Greenwald, A. G., \& Banaji, M. R. (1986). Words high and low in pleasantness as rated by male and female college students. Behavior Research Methods, Instruments, and Computers, 18(3), 299-303. doi: 10.3758/BF03204403

Bers, T. H., \& Smith K. E. (1991). Persistence of community college students: The influence of student intent and academic and social integration. Research in Higher Education, 32(5), 529-556. doi: 10.1007/BF00992627

Braxton, J.-M., Bray, N. J., \& Berger, J.-B. (2000). Faculty teaching skills and their influence on the college student departure process. Journal of College Student development, 41(2), 215-227.

Braxton, J.-M., Hirschy, A. S., \& McClendon, S. A. (2004). Understanding and reducing college student departure. San Francisco: Jossey-Bass.

Cabrera, A. F., Castaneda, M. B., Nora, A., \& Hengstler, D. (1992). The convergence between two theories of college persistence. Journal of Higher Education, 63(2), 143-164. doi: 10.2307/1982157

Chassin, L., Presson, C., Seo, D., Sherman, S. J., Macy, J., Wirth, R. J., \& Curran, P. (2008). Multiple trajectories of cigarette smoking and the intergenerational transmission of smoking: A multigenerational, longitudinal study of a Midwestern community sample. Health Psychology, 27, 819-828. doi: 10.1037/0278-6133.27.6.819

Cohen, J. (1988). Statistical power analysis for the behavioral sciences ( $2^{\text {nd }}$ ed). Hillsdale, NJ: Erlbaum. 
Corneille, O., \& Stahl, C. (in press). Associative Attitude Learning. Getting Closer to Evidence and how it relates to attitude models. Personality and Social Psychology Review. doi: $10.1177 / 1088868318763261$

DaDeppo, L. (2009). Integration factors related to the academic success and intent to persist of college students with learning disabilities. Learning Disabilities Research \& Practice, 24(3), 122-131. doi: 10.1111/j.1540-5826.2009.00286.x

Davis, L. E., Ajzen, I., Saunders, J., \& Williams, T. (2002). The decision of African American students to complete high school: An application of the theory of planned behavior. Journal of Educational Psychology, 94(4), 810-819. doi: 10.1037//0022-0663.94.4.810

Eccles, J. S., \& Wigfield, A. (2002). Motivational beliefs, values, and goals. Annual Review of Psychology, 53, 109-132. doi:10.1146/annurev.psych.53.100901.135153

Finnie, R., \& Qiu, H. (2008). The patterns of persistence in post-secondary education in Canada: Evidence from the YITS-B dataset. Toronto, ON: Educational Policy Institute.

Fishbein, M., \& Ajzen, I. (2010). Predicting and changing behavior: The reasoned action approach. New York: Psychology Press (Taylor \& Francis).

Friese, M., Hofmann, W., \& Schmitt, M. (2008). When and why do implicit measures predict behaviour? Empirical evidence for the moderating role of opportunity, motivation, and process reliance. European Journal of Social Psychology, 19(1), 285-338. doi: 10.1080/10463280802556958

Gast, A., \& De Houwer, J. (2012). Evaluative conditioning without directly experienced pairings of the conditioned and the unconditioned stimuli. The Quarterly Journal of Experimental Psychology, 65(9), 1657-1674. doi: 10.1080/17470218.2012.665061

Gati, I., Landman, S., Davidovitch, S., Asulin-peretz, L., \& Gadassi, R. (2010). From career decisionmaking styles to career decision-making profiles : A multidimensional approach. Journal of Vocational Behavior, 76(2), 277-291. doi: 10.1016/j.jvb.2009.11.001

Greenwald, A. G., Banaji, M. R., Rudman, L. A., Farnham, S. D., Nosek, B. A., \& Mellott, D. S. (2002). A unified theory of implicit attitudes, stereotypes, self-esteem, and self-concept. Psychological Review, 109(1), 3-25. doi: 10.1037//0033-295X.109.1.3

Greenwald, A. G., Mcghee, D. E., \& Schwartz, J. L. K. (1998). Measuring individual differences in implicit cognition: The Implicit Association Test. Journal of Personality and Social Psychology, 74(6), 1464-1480. doi: 10.1037/0022-3514.74.6.1464

Hae-Young, K. (2013). Statistical notes for clinical researchers: assessing normal distribution using skewness and kurtosis. Restor Dent Endod, 38(1), 52-54. doi: 10.5395/rde.2013.38.1.52

Hahn, A., Judd, C. M., Hirsh, H. K., \& Blair, I. V. (2014). Awareness of implicit attitudes. Journal of Experimental Psychology: General, 143(3), 1369-1392. doi: 10.1037/a0035028

Hofmann, W., Gschwendner, T., Nosek, B. A., \& Schmitt, M. (2005). What moderates implicit-explicit consistency? European Review of Social Psychology, 16(1), 335-390. doi: $10.1080 / 10463280500443228$

Houme, K. P. (2009). Application de la théorie du comportement planifié pour prédire la persévérance des étudiants en sciences naturelles de l'Université de Lomé (Togo) (Doctoral dissertation). Retrieved from http://www.theses.ulaval.ca/2009/26821/26821.pdf

McEachan, R. R. C., Conner, M., Taylor, N. J., \& Lawton, R. J. (2011). Prospective prediction of healthrelated behaviors with the theory of planned behavior: A meta-analysis. Health Psychology Review, 5(2), 97-144. doi:10.1080/17437199.2010.521684

Kurdi, B., \& Banaji, M. R. (2017). Repeated evaluative pairings and evaluative statements: How effectively do they shift implicit attitudes? Journal of Experimental Psychology: General, 146(2), 194-213. http://doi.org/10.1037/xge0000239

National Center for Education Statistics [NCES] (2016). Persistence and Attainment of 2011-12 FirstTime Postsecondary Students After 3 Years (Research Report n²016-401). Washington: Department of Education, Office of Educational Research and Improvement.

Neuville, S., Frenay, M., \& Bourgeois, E. (2007). Task value, self-efficacy and goal orientations: Impact on self-regulated learning. Psychologica Belgica, 47(1-2), 95-117. doi : 10.5334/pb-47-1-95 
Nock, M. K., Park, J. M., Finn, C. T., Deliberto, T. L., Dour, H. J., \& Banaji, M. R. (2010). Measuring the "suicidal mind:" Implicit cognition predicts suicidal behavior. Psychological Science, 21(4), 511517. doi: 10.1177/0956797610364762

Nora, A., Cabrera, A., Hagdorn, L. S., \& Pascarella, E. (1996). Differential impacts of academic and social experiences on college-related behavior outcomes across different ethnic and gender groups at four-year institutions. Research in Higher Education, 37(4), 427-451. doi: 10.1007/BF01730109

Nosek, B. A., Banaji, M. R., \& Greenwald, A. G. (2002). Math = Male, Me = Female, Therefore Math = Me. Journal of Personality and Social Psychology, 83(1), 44-59. doi: 10.1037//0022-3514.83.1.44

Nosek, B. A., Banaji, M. R., \& Greenwald, A. G. (2010). Project Implicit. Retrieved from https://implicit.harvard.edu/implicit/

Nosek, B. A., Bar-Anan, Y., Sriram, N., Axt, J., \& Greenwald, A. G. (2014). Understanding and using the brief implicit association test: Recommended scoring procedures. PLOS ONE 9(12), 1-31. doi:10.1371/journal.pone.0110938

Organization for Economic Cooperation and Development [OECD] (2013). Regards sur l'éducation. Retrieved from http://www.oecd.org/fr/education/rse-indicateurs.htm

Osgood, C. E., Suci, G. J., \& Tannenbaum, P. H. (1957). The measurement of meaning. Urbana: University of Illinois Press.

Otero, R., Rivas, O., \& Rivera, R. (2007). Predicting persistence of Hispanic students in their first year of college. Journal of Hispanic Higher Education, 6(2), 163-173. doi:10.1177/1538192706298993

Ottaway, S. A., Hayden, D. C., \& Oakes, M. A. (2001). Implicit attitudes and racism: Effects of word familiarity and frequency on the implicit association test. Social Cognition, 19(2), 97-144. doi: 10.1521/soco.19.2.97.20706

Pascarella, E., Duby, P., \& Iverson, B. (1983). A text and reconceptualization of a theoretical model of college withdrawal in a commuter institution setting. Sociology of Education, 56(2), 88-100. doi: $10.2307 / 2112657$

Pascarella, E., \& Terenzini, P. (2005). How College Affects Students: A Third Decade of Research (2 ${ }^{\text {nd }}$ ed.). Hoboken, NJ: John Wiley \& Sons.

Pritchard, M. E., \& Wilson, G. S. (2003). Using emotional and social factors to predict student success. Journal of College Student Development, 44(1), 18-28. doi: 10.1353/csd.2003.0008

Ratelle, C. F., Larose, S., Guay, F., \& Senécal, C. (2005). Perceptions of parental involvement and support as predictors of college students'persistence in a science curriculum. Journal of Family Psychology, 19(2), 286-293. doi :10.1037/0893-3200.19.2.286

Robbins, S. B., Lauver, K., Le, H., Davis, D., Langley, R., \& Carlstrom, A. (2004). Do psychosocial and study skill factors predict college outcomes? A meta-analysis. Psychological Bulletin, 130(2), 261288. doi:10.1037/0033-2909.130.2.261

Roland, N., Frenay M., \& Boudrenghien, G. (2016a). Understanding academic persistence through the theory of planned behaviour: Normative factors under investigation. Journal of College Student Retention: Research, Theory \& Practice. doi: 10.1177/1521025116656632

Roland, N., Frenay, M., \& Boudrenghien, G. (2016b). Towards a better understanding of academic persistence among freshmen: A qualitative approach. Journal of Education and Training Studies, 4(12), 175-188. doi: 10.11114/jets.v4i12.1904

Romainville, M., \& Michaut, C. (2012), Réussite, échec et abandon dans l'enseignement supérieur. Bruxelles: De Boeck.

Rothermund, K., \& Wentura, D. (2004). Underlying processes in the Implicit Association Test (IAT): Dissociating salience from associations. Journal of Experimental Psychology: General, 133(2), 139165. doi: 10.1037/0096-3445.133.2.139

Sandler, M. E. (2000). Career decision-making self-efficacy, perceived stress, and an integrated model of student persistence: A structural model of finances, attitudes, behavior, and career development. Research in Higher Education, 41(5), 537-580. doi: 10.1023/A:1007032525530

Schmitz, J., \& Frenay, M. (2013). La persévérance en première année à l'université : Rôle des expériences en classe, de l'intégration sociale et de l'ajustement émotionnel. In S. Neuville, M. Frenay, B. Noël, 
\& V. Wertz (Eds.), Persévérer et réussir à l'Université. Louvain-la-Neuve: Presses universitaires de Louvain.

Schmitz, J., Frenay, M., Neuville, S., Boudrenghien, G., Wertz, V., Noël, B., \& Eccles, J. (2010). Étude de trois facteurs clés pour comprendre la persévérance à l'université. Revue française de pédagogie, 172, 43-61. doi : 10.4000/rfp. 2217

Schubert, T. W., \& Otten, S. (2002). Overlap of self, ingroup, and outgroup: Pictorial measures of selfcategorization. Self and identity, 1(4), 353-376. doi: 10.1080/152988602760328012

Sheeran, P., Orbell, S., \& Trafimow, D. (1999). Does the temporal stability of behavioural intentions moderate intention-behavior and past behavior-future behavior relations? Personality and Social Psychology Bulletin, 25(6), 724-734. doi:10.1177/0146167299025006007

Srivastava, S. B., \& Banaji, M. R. (2011). Culture, cognition, and collaborative networks in organizations. American Sociological Review, 76(2), 207-233. doi: 10.1177/0003122411399390

Tinto, V. (2006). Research and practice of student retention: What next? Journal of College Student Retention, 8(1), 1-19. doi: 10.2190/C0C4-EFT9-EG7W-PWP4

Van Dessel, P., De Houwer, J., Gast, A., \& Smith, C. T. (2015). Instruction-based approach-avoidance effects. Changing stimulus evaluation via the mere instruction to approach or avoid stimuli. Experimental Psychology, 62, 161-169. doi: 10.1027/1618-3169/a000282

Vermandele, C., Dupriez, V., Maroy, C., \& Van Campenhoudt, M. (2012). Réussir à l'université : L'influence persistante du capital culturel de la famille. Les Cahiers de recherche en éducation et formation, $n^{\circ} 87$.

Vuong, M., Brown-Welty, S., \& Tracz, S. (2010). The effects of self-efficacy on academic success of first-generation college sophomore students. Journal of College Student Development, 51(1), 50-64. doi : 10.1353/csd.0.0109

Wiers, R. W., Van Woerden, N., Smulders, F. T. Y., \& De Jong, P. J. (2002). Implicit and explicit alcohol-related cognitions in heavy and light drinkers. Journal of Abnormal Psychology, 111(4), 648-658. doi: 10.1037/0021-843X.111.4.648

Wright, S. L., Jenkins-Guarnieri, M. A., \& Murdock, J. L. (2012). Career development among first-year college students: College self-efficacy, student persistence, and academic success. Journal of Career Development, 40(4), 292-310. doi: 10.1177/0894845312455509

Zerhouni, O., Rougier, M., \& Muller, D. (2016). "Who (really) is Charlie?" French cities with lower implicit prejudice toward Arabs demonstrated larger participation rates in Charlie Hebdo rallies. International Review of Social Psychology, 29(1), 69-76. doi: 10.5334/irsp.50 